\title{
Effect of Prenatal Polycyclic Aromatic Hydrocarbons Exposure on Birth Outcomes: The Polish Mother and Child Cohort Study
}

\author{
Kinga Polanska, ${ }^{1}$ Gerhard Dettbarn, ${ }^{2}$ Joanna Jurewicz, ${ }^{1}$ Wojciech Sobala, ${ }^{1}$ Per Magnus, ${ }^{3}$ \\ Albrecht Seidel, ${ }^{2}$ and Wojciech Hanke ${ }^{1}$ \\ ${ }^{1}$ Department of Environmental Epidemiology, Nofer Institute of Occupational Medicine, 8 Teresy Street, 91-348 Lodz, Poland \\ ${ }^{2}$ Biochemical Institute for Environmental Carcinogens, Prof. Dr. Gernot Grimmer-Foundation, Lurup 4, \\ D-22927 Großhansdorf, Germany \\ ${ }^{3}$ Division of Epidemiology, Norwegian Institute of Public Health, P.O. Box 4404, Nydalen, N-0403 Oslo, Norway
}

Correspondence should be addressed to Kinga Polanska; kinga@imp.lodz.pl

Received 28 February 2014; Accepted 3 July 2014; Published 22 July 2014

Academic Editor: Hartmut Jaeschke

Copyright (C) 2014 Kinga Polanska et al. This is an open access article distributed under the Creative Commons Attribution License, which permits unrestricted use, distribution, and reproduction in any medium, provided the original work is properly cited.

\begin{abstract}
The aim of this study was to assess the impact of PAH exposure on various anthropometric measures of birth outcomes. The study population consisted of 210 nonsmoking pregnant women. Urine samples collected between 20th and 24th week of pregnancy were used for analysis of the following PAH metabolites: 1-, 2-, 3-, 4-, and 9-hydroxyphenanthrene (1-, 2-, 3-, 4-, and 9-OH-PHE), 1-hydroxypyrene (1-OH-PYR), 1,6 + 1,8-dihydroxypyrene (DI-OH-PYR), phenanthrene trans-1,2-dihydrodiol (PHE-1,2-diol), and phenanthrene trans-9,10-dihydrodiol (PHE-9,10-diol) by gas chromatography-mass spectrometry. Environmental tobacco smoke exposure (ETS) was assessed by cotinine level in saliva using a stable isotope dilution LC-ESI-MS/MS method. The mean PAH metabolite concentrations were in the range of $0.15 \mu \mathrm{g} / \mathrm{g}$ creatinine for $9-\mathrm{OH}-\mathrm{PHE}$ to $5.9 \mu \mathrm{g} / \mathrm{g}$ creatinine for PHE-9,10-diol. It was shown that none of the individual PAH exposure markers demonstrate a statistically significant influence on birth outcomes. Interestingly a statistically significant association was found between the sum of $\mathrm{OH}-\mathrm{PHE}$ along with cotinine level and the cephalization index after adjusting for potential confounders $(P=0.04)$. This study provides evidence that combined exposure of pregnant women to common environmental pollutants such as PAH and ETS might adversely affect fetal development. Thus, reduction of human exposure to these mixtures of hazardous compounds would in particular result in substantial health benefits for newborns.
\end{abstract}

\section{Introduction}

Polycyclic aromatic hydrocarbons (PAH) are widespread environmental pollutants that are generated in the course of incomplete combustion and pyrolysis of organic materials such as fuel, coal, wood, garbage, and tobacco. The general population is unavoidably exposed to $\mathrm{PAH}$ through polluted ambient air from a variety of sources such as motor vehicles and trucks, coal-fired power plants, residential heating, and environmental tobacco smoke, as well as through contaminated food including charcoal-grilled and smoked meat [14].

PAH occur in the environment as a complex mixture of hazardous genotoxic compounds and resulting human exposure raises public health concerns regarding their potential health implications. The prototypic PAH benzo[ $[a]$ pyrene has been classified by the International Agency for Research on Cancer (IARC) as human carcinogen, whereas other PAH are categorized as probably or possibly carcinogenic to humans [1]. Furthermore, reproductive epidemiology studies provide evidence that the developing fetus and infant are sensitive to these environmental toxicants. PAH have been found in placental tissues [5] and umbilical cord blood [6], which suggest that transplacental transfer of these chemicals to the fetus can have a significant impact on fetal development including increased risk of intrauterine growth restriction (IUGR), small-for-gestational age (SGA), and preterm delivery [6-13]. In some studies in addition to anthropometric parameters at birth, such as birth weight and length as well as head and chest circumference, the ponderal index, indicator for thinness of a newborn, and cephalization index, indicator of brain-sparing, were calculated $[5,12,14]$. Both of 
these indices have been significantly correlated with severe IUGR as well as with poor neurodevelopmental outcomes $[15,16]$ and subsequent morbidity and mortality [12]. In the study performed by Choi et al. [12] a 1-in-unit increase in prenatal PAH exposure was associated with a $0.04 \%$ increase in cephalization index. It has been recently demonstrated that prenatal exposure to $\mathrm{PAH}$ may have an effect on the infants' neurodevelopment, including decreased cognitive and motor functions, a reduced child IQ, and an increased risk of behavioral problems [17-21].

The aim of this study was to assess the impact of PAH exposure as determined by urinary biomarkers on various anthropometric measures of birth outcomes based on the Polish Mother and Child Cohort Study (REPRO_PL cohort).

\section{Material and Methods}

2.1. Study Design and Population. The present study was based on data from the Polish Mother and Child Cohort (REPRO_PL, http://www.repropl.com/). The mothers' recruitment and follow-up procedures have previously been published in detail [22]. Briefly, subjects were recruited through maternity units or clinics in selected regions of Poland. The recruitment was restricted to women being in single pregnancies, being not assisted with reproductive technology, and having up to 12 weeks of gestation. All women with serious chronic diseases specified in the study protocol were excluded from the study.

The current analysis was focused on pregnant women who were nonsmokers and had no history of occupational $\mathrm{PAH}$ exposure. The smoking status of pregnant women was verified by measuring cotinine levels in saliva collected between the 20th and 24th week of gestation using a stable isotope dilution LC-ESI-MS/MS method (high performance liquid chromatography coupled with tandem mass spectrometry/positive electrospray ionization) [23]. All the women with the cotinine levels above $10 \mathrm{ng} / \mathrm{mL}$ were considered smokers and were excluded from the analysis. The cut-off point for the cotinine level was selected based on recommendations made by SRNT Subcommittee on Biochemical Verification [24].

The study was approved by the Ethical Committee of the Nofer Institute of Occupational Medicine, Lodz, Poland, and a written consent was obtained from all the subjects.

2.2. Exposure Variables. The urine samples were collected from the pregnant women at the time of their second prenatal clinic visit scheduled within the study (between 20th and 24th week of gestation) into polypropylene cups. The samples were stored at $-20^{\circ} \mathrm{C}$ and aliquots were shipped in a frozen state to the Biochemical Institute for Environmental Carcinogens, Prof. Dr. Gernot Grimmer-Foundation, Großhansdorf, Germany, for the analysis of urinary PAH metabolites. The details of analysis of PAH metabolites in biological samples were published elsewhere [25].

1-Hydroxypyrene (1-OH-PYR) was commercially available from Sigma-Aldrich (Taufkirchen, Germany). 1-, 2-, 3-, and 4-hydroxyphenanthrene (OH-PHE), phenanthrene trans-1,2-dihydrodiol (PHE-1,2-diol), and phenanthrene trans-9,10-dihydrodiol (PHE-9,10-diol) were synthesized as described previously [26]. 9-OH-PHE was purchased from Sigma-Aldrich (Taufkirchen, Germany) and further purified by flash chromatography on silica gel using dichloromethane as an eluent. Both 1,6- and 1,8-dihydroxypyrene were synthesized in accordance with Vollmann et al. (1937) [27]. $\mathrm{D}_{10}$-Pyrene and $\mathrm{d}_{12}$-chrysene were commercially available from Cambridge Isotope Laboratories Inc. (50 Frontage Road, Andover, USA). 6-Fluoro-1,2-dihydroxy1,2-dihydrophenanthrene used as an internal standard and all methyl ether derivatives of PAH metabolites necessary for calibration were synthesized at BIU. $\beta$-Glucuronidase (EC 3.2.1.31)/arylsulfatase (EC 3.1.6.1) from Helix pomatia was purchased from Roche Diagnostic GmbH (Mannheim, Germany).

The analyses by gas chromatography-mass spectrometry (GC-MS) were carried out with an Agilent 5890N instrument equipped with a split/splitless injector and an Agilent 5972 mass selective detector (MSD) operated in the single ion monitoring (SIM) mode. For GC separation of the analytes, a Zebron ZB-35 capillary (Phenomenex; $30 \mathrm{~m}$ (length) $\times$ $0.25 \mathrm{~mm}$ (inner diameter), $0.25 \mu \mathrm{m}$ (film thickness)) was applied.

Determination of phenolic $\mathrm{PAH}$ metabolites was performed, as previously described, with several modifications [28]. This methodology has been further developed for a direct determination of PHE-1,2-diol and PHE-9,10-diol. Given the available amount of urine from the Polish Mother and Child Cohort for the present study the number of women for whom the analysis was performed was 210 for PHE-1,2diol and PHE-9,10-diol and 104 for hydroxyphenanthrenes and hydroxypyrenes.

Creatinine level was measured using the Jaffe colorimetric method with a working range of $0.05-5.00 \mathrm{~g}$ creatinine/L. Urine samples with a creatinine concentration lower than $0.3 \mathrm{~g} / \mathrm{L}$ or higher than $3.0 \mathrm{~g} / \mathrm{L}$ were excluded from the analysis.

2.3. Outcome Variables. The following anthropometric measures at birth, filled in by gynecologists/neonatologists, were considered in the analysis: birth weight (in grams), birth length, and head and chest circumference (in centimeters). In addition, ponderal index (PI) [birth weight (g)/birth length $\left(\mathrm{cm}^{3}\right) \times 10^{2}$ ] and cephalization index (CI) [head circumference $(\mathrm{cm}) /$ birth weight $(\mathrm{g}) \times 10^{4}$ ] were calculated.

2.4. Potential Confounders. The mothers filled in a detailed questionnaire concerning sociodemographic characteristics (age, marital status, parity, maternal education, and employment), medical history, previous and current pregnancies, and lifestyle variables (place of residence, history of passive smoking, alcohol consumption during pregnancy, frequency of grilled or fried food intake based on the food frequency questionnaire, and home characteristics). The questionnaires were administered 3 times during pregnancy (at enrolment: 8th-12th week of gestation, second visit: 20th-24th week of gestation, and third visit: 30th-34th week of gestation) during personal interviews by trained midwives. Factors 


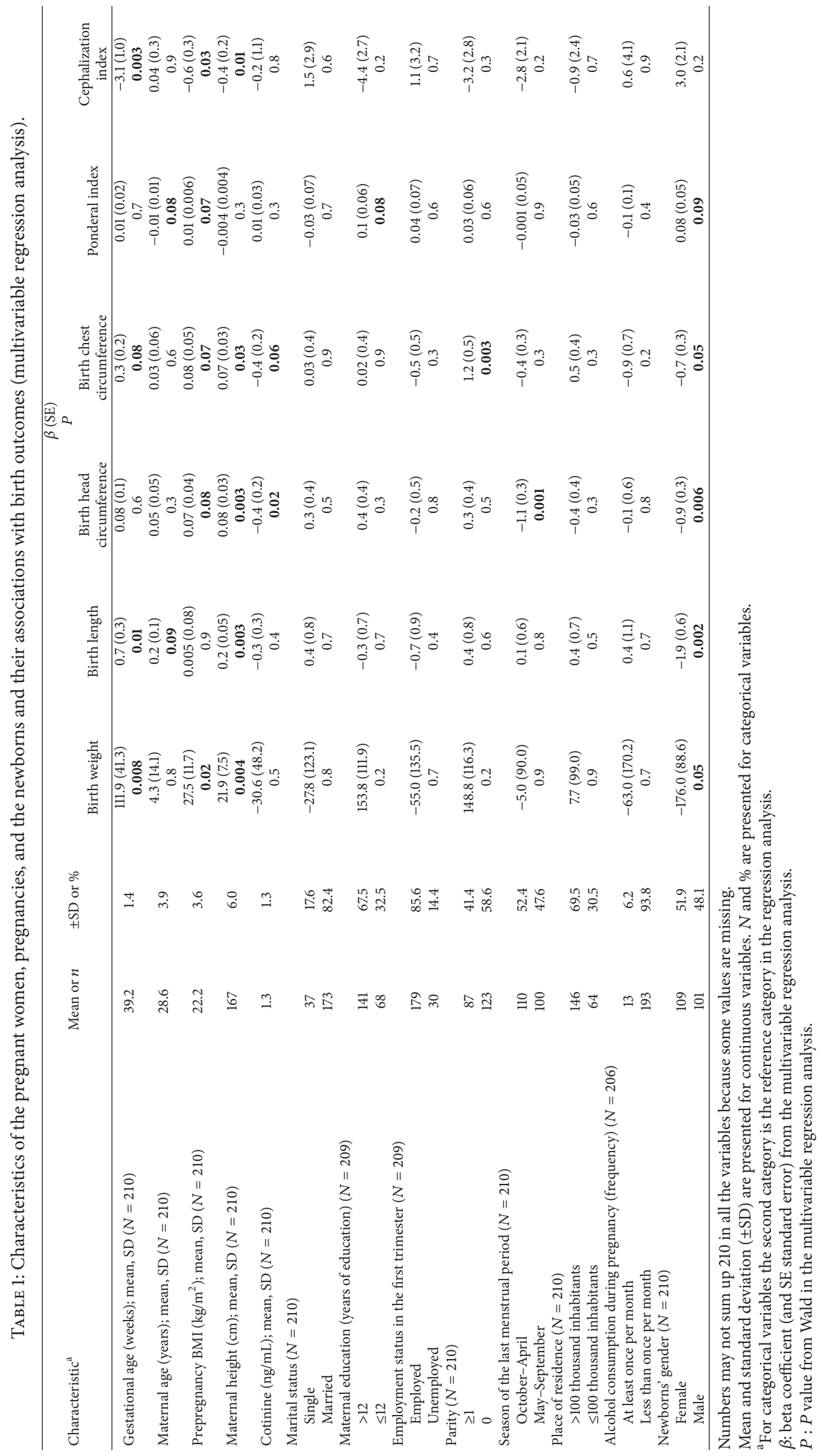


TABLE 2: Newborn anthropometric indicators.

\begin{tabular}{lcccc}
\hline & Median & Mean & \pm SD & Range \\
\hline Birth weight $(\mathrm{g}) \mathrm{N}=210$ & 3400.0 & 3417.3 & 460.3 & $2150.0-5100.0$ \\
Child length $(\mathrm{cm}) \mathrm{N}=210$ & 55.0 & 55.2 & 2.8 & $48.0-64.0$ \\
$\begin{array}{l}\text { Head circumference }(\mathrm{cm}) \\
N=208\end{array}$ & 34.0 & 34.3 & 1.6 & $31.0-39.0$ \\
$\begin{array}{l}\text { Chest circumference }(\mathrm{cm}) \\
N=208\end{array}$ & 33.0 & 33.3 & 1.8 & $27.0-39.0$ \\
$\begin{array}{l}\text { Ponderal index }\left(\mathrm{g} / \mathrm{cm}^{3}\right) \\
N=207\end{array}$ & 2.0 & 2.0 & 0.2 & $1.5-2.8$ \\
$\begin{array}{l}\text { Cephalization index }(\mathrm{cm} / \mathrm{g}) \\
N=208\end{array}$ & 100.5 & 101.9 & 12.2 & $74.5-148.8$ \\
\hline
\end{tabular}

that could confound the relationship between PAH exposure and anthropometric parameters at birth were selected a priori from a set of characteristics and were tested in a multivariable regression analysis (Table 1). The following potential confounders were considered: gestational age, child gender, passive smoking, and alcohol consumption during pregnancy, maternal age, height, prepregnancy BMI, maternal, marital, educational, and employment status, parity, the place of residence, and season of the last menstrual period. Pregnancy duration was estimated using the date of the last menstrual period (LMP) or ultrasound if it differed from the LMP based estimate by $>2$ weeks. Environmental tobacco smoke (ETS) exposure was assessed based on the cotinine levels in saliva collected at the same visit as the urine samples for PAH exposure assessment (20th-24th week of gestation) using a stable isotope dilution LC-ESI-MS/MS method [23].

2.5. Statistical Analyses. Continuous data were expressed as means \pm standard deviations $( \pm S D)$, as well as the 50th and 95th (for PAH metabolites) percentiles and ranges. Categorical data were presented as numbers and frequencies (\%). The creatinine-corrected urinary concentrations of PAH metabolites were analyzed. PAH metabolites and cotinine levels were log-transformed. The 2 following sets of confounders were considered: Model 1: gestational age at birth and child gender; Model 2: all potential confounders significant at a 0.1 level in a multivariable regression (Table 1 ).

Robust linear regression was performed for each $\mathrm{PAH}$ metabolite and for the sum of selected metabolites. In the multiple regression analysis, data were expressed as regression coefficients $(\beta)$ with their standard errors and $P$ values. We considered $P$ values less than $0.05(P \leq$ $0.05)$ as statistically significant. The statistical analyses were performed using R 3.0.1 statistical package.

\section{Results}

3.1. Characteristics of the Study Participants, Exposure, and Outcomes Variables. Characteristics of mothers, pregnancy, and newborns and their relation to birth outcomes are described in Tables 1 and 2.

The mean maternal age was $28.6( \pm 3.9)$ years (Table 1$)$. Most of the women (68\%) declared more than 12 years of education and were employed in the first trimester of pregnancy $(86 \%)$. Also, majority of the mothers were married $(82 \%)$, and $59 \%$ had no children prior to the current pregnancy. The mean prepregnancy BMI was $22.2 \mathrm{~kg} / \mathrm{m}^{2}$ $\left( \pm 3.6 \mathrm{~kg} / \mathrm{m}^{2}\right)$. About $70 \%$ of the women indicated a big city as their place of residence. About $6 \%$ of the women consumed alcohol at least once per month in the pregnancy period. The mean cotinine level in saliva collected in the second trimester of pregnancy was $1.3 \mathrm{ng} / \mathrm{mL}( \pm 1.3 \mathrm{ng} / \mathrm{mL})$.

About $52 \%$ of the children were girls (Table 1). On average the children were born at the 39th week of gestation $( \pm 1.4$ week) with the mean birth weight of $3417 \mathrm{~g}( \pm 460 \mathrm{~g})$ and length of $55 \mathrm{~cm}( \pm 2.8 \mathrm{~cm})$ (Table 2$)$. The mean newborn's head circumference was $34 \mathrm{~cm}( \pm 1.6 \mathrm{~cm})$ and chest circumference was $33 \mathrm{~cm}( \pm 1.8 \mathrm{~cm})$.

The mothers who had higher prepregnancy BMI and who were taller had infants with higher birth weight $(P \leq$ $0.02)$. Boys were bigger and weighed more than girls $(P \leq$ $0.05)$. Child birth length and head and chest circumference increased along with the increasing maternal height $(P \leq$ 0.03). In addition, an inverse correlation was observed for cotinine level in saliva and child birth head and chest circumference $(P \leq 0.06)$. Gestational age was associated with child birth weight and length $(P \leq 0.01)$.

Characteristics of exposure variables are presented in Table 3. The mean PAH concentrations ranged from $0.15 \mu \mathrm{g} / \mathrm{g}$ creatinine for 9 -OH-PHE $( \pm 0.2 \mu \mathrm{g} / \mathrm{g}$ creatinine $)$ to $5.9 \mu \mathrm{g} / \mathrm{g}$ creatinine for PHE-9,10-diol $( \pm 10.6 \mu \mathrm{g} / \mathrm{g}$ creatinine $)$.

3.2. Association between Prenatal PAH Exposure and Various Anthropometric Measures of Birth Outcomes. In the model adjusted for gestational age and newborns' gender, none of the analyzed PAH metabolites was alone associated with any of the anthropometric measures at birth (Table 4). In analysis with adjustment for additional confounders the adverse effect of $\sum \mathrm{OH}-\mathrm{PYR}$ on chest circumference was of borderline significance (Table 5). Interestingly, a significant interaction effect of the sum of OH-PHE and the cotinine level on cephalization index was noticed after adjusting for gestational age, newborns' gender, maternal prepregnancy BMI, and maternal height (Table 5), indicating that combined high PAH and high ETS exposure positively correlated with the ratio of head circumference to the birth weight.

The same pattern was observed for the sum of PHEdiol, but the association was of borderline significance $(P$ for interaction $=0.06$ ).

\section{Discussion}

In this study we have not found any statistically significant effects of individual urinary biomarker of PAH exposure on birth outcomes. However, a significant interaction effect of the sum of OH-PHE and the cotinine level in saliva as a measure of PAH and ETS exposure, respectively, on the cephalization index was noticed $(P=0.04)$. This association is of potential concern since poor pregnancy outcomes may be linked to later neurodevelopmental and other health problems. 
TABle 3: Descriptive statistics of the PAH metabolites ( $\mu \mathrm{g} / \mathrm{g}$ creatinine).

\begin{tabular}{|c|c|c|c|c|c|c|}
\hline PAH metabolites & $N$ & Mean & $\pm \mathrm{SD}$ & Median & 95th percentile & Range \\
\hline 1-OH-PHE & 104 & 1.50 & 1.27 & 1.10 & 4.14 & $0.30-8.64$ \\
\hline 2-OH-PHE & 104 & 0.61 & 0.50 & 0.43 & 1.47 & $0.13-3.07$ \\
\hline 3-OH-PHE & 104 & 0.45 & 0.43 & 0.31 & 1.27 & $0.05-2.79$ \\
\hline 4-OH-PHE & 104 & 0.17 & 0.14 & 0.13 & 0.48 & $0.02-0.70$ \\
\hline 9-OH-PHE & 104 & 0.15 & 0.20 & 0.10 & 0.43 & $0.004-1.70$ \\
\hline$\sum \mathrm{OH}-\mathrm{PHE}$ & 104 & 2.88 & 2.43 & 2.12 & 7.26 & $0.61-16.77$ \\
\hline PHE-1,2-diol & 210 & 4.09 & 4.53 & 2.41 & 12.70 & $0.06-26.72$ \\
\hline PHE-9,10-diol & 210 & 5.93 & 10.57 & 2.70 & 23.88 & $0.05-94.15$ \\
\hline$\sum$ PHE-diol & 210 & 10.01 & 13.35 & 6.05 & 34.44 & $0.24-115.35$ \\
\hline 1-OH-PYR & 104 & 0.43 & 0.30 & 0.35 & 0.97 & $0.06-1.64$ \\
\hline DI-OH-PYR & 104 & 0.30 & 0.33 & 0.21 & 0.84 & $0.002-2.52$ \\
\hline$\sum \mathrm{OH}-\mathrm{PYR}$ & 104 & 0.73 & 0.57 & 0.56 & 1.75 & $0.06-4.17$ \\
\hline
\end{tabular}

1-, 2-, 3-, 4-, and 9-OH-PHE, 1-, 2-, 3-, 4-, and 9-hydroxyphenanthrene; $\sum$ OH-PHE, sum of 1-, 2-, 3-, 4-, and 9-OH-PHE; PHE-1,2-diol, phenanthrene trans1,2-dihydrodiol; PHE-9,10-diol, phenanthrene trans-9,10-dihydrodiol; $\sum$ PHE-diol, sum of PHE-1,2-diol and PHE-9,10-diol; 1-OH-PYR, 1-hydroxypyrene; DIOH-PYR, sum of 1,6- and 1,8-dihydroxypyrenes; $\sum$ OH-PYR, sum of 1-OH-PYR and DI-OH-PYR.

In our previous analysis (with $20 \%$ of the population classified as smokers) the association between 1-OH-PYR and biometric parameters at birth was not statistically significant after controlling for the cotinine level in saliva as the biomarker of smoking status [14]. Taking into consideration the smoking status as significant confounder, the current analysis was restricted to the nonsmoking women with cotinine levels in saliva below $10 \mathrm{ng} / \mathrm{mL}$ [24]. Another very important feature of the current study, compared to the previous one, is the analysis of a variety of different urinary PAH metabolites as biomarkers in addition to 1-OH-PYR, which has resulted in a more comprehensive assessment of PAH exposure.

4.1. Exposure Assessment. A variety of different PAH metabolites in the urine collected during the second trimester of pregnancy were selected as the biomarkers of exposure. There have been concerns whether the single spot urine tests represent the long-term exposure. The analysis performed by Choi et al. (2008) indicated that measurements during the third trimester were significantly lower compared with the second trimester, whereas those during the first trimester were not [29]. However, our previous analysis based on a subsample of the REPRO_PL cohort indicated no differences between 1-OH-PYR levels in urine collected during the second and third trimesters of pregnancy (second trimester 1-OH-PYR geometric mean $(\mathrm{GM})=0.4 \pm 2.4 \mu \mathrm{g} / \mathrm{g}$ creatinine and third trimester $\mathrm{GM}=0.4 \pm 2.4 \mu \mathrm{g} / \mathrm{g}$ creatinine; $P=0.7$ ) [30].

Although the studies evaluating the impact of $\mathrm{PAH}$ exposure on pregnancy outcomes exist, it is difficult to compare their results to these obtained in the current study. This results from the fact that researchers select different PAH metabolites for their analysis so direct comparison of the magnitude of exposure is not possible. However, based on the analysis by Choi et al. (2006), personal airborne PAH exposure was 10 -fold higher in Krakow than in NYC [11]. In addition, multiple linear regression analysis performed by Tonne at al. (2004) on pregnant minority women in NYC revealed associations between personal PAH exposures and season of the year, time spent outdoors, residential heating, and indoor burning of incense [31]. Our current results (although based on different biomarkers of exposure) also indicate high PAH exposure. The median 1-OH-PYR level observed in the pregnant women's urine $(0.35 \mu \mathrm{g} / \mathrm{g}$ creatinine $)$ was higher than that noted in the INMA cohort of nonsmoking pregnant women in Valencia $(0.1 \mu \mathrm{g} / \mathrm{g}$ creatinine) and postpartum nonsmoking women from Saudi Arabia $(0.05 \mu \mathrm{g} / \mathrm{g}$ creatinine) [5, 32]. The Human Biomonitoring Commission of the German Federal Environment Agency established 1$\mathrm{OH}-\mathrm{PYR}$ levels in urine of $0.3 \mu \mathrm{g} / \mathrm{g}$ creatinine as the reference value for the nonsmoking general population aged between 3 and 69 years $[33,34]$. In the present study, this reference value was much higher $(1.0 \mu \mathrm{g} / \mathrm{g}$ creatinine). It is important to notice that most of the women included in our analysis lived in a big city (Lodz) which can be the reason for the higher 1-OH-PYR level. This was confirmed by the stationary ambient air monitoring data (from Voivodeship Inspectorates for Environmental Protection), which indicated that the annual mean $\mathrm{BaP}$ level in various locations within Lodz was substantially higher than the target value of $1 \mathrm{ng} / \mathrm{m}^{3}$ recently set into force by the European Commission [35, 36].

4.2. Effect of Exposure on Neonatal Anthropometric Measures. The association between urinary PAH metabolite levels or PAH-DNA damage and reduced biometric measures at birth has been reported in some, but not all, studies. For example, the study performed in the Czech Republic indicated that ambient PAH exposure in the early stage of pregnancy significantly increased the risk of intrauterine growth restriction $(\mathrm{OR}=1.2 ; 95 \%$ CI 1.1-1.4) [7]. The analysis performed in Poland (Krakow and Limanowa) by Perera et al. (1998), with high PAH exposure levels, indicated that newborns whose levels of PAH-DNA adducts were above the median had significantly decreased birth length and weight and head circumference [8]. Determination of airborne PAH by personal air sampling indicated that such exposure was 


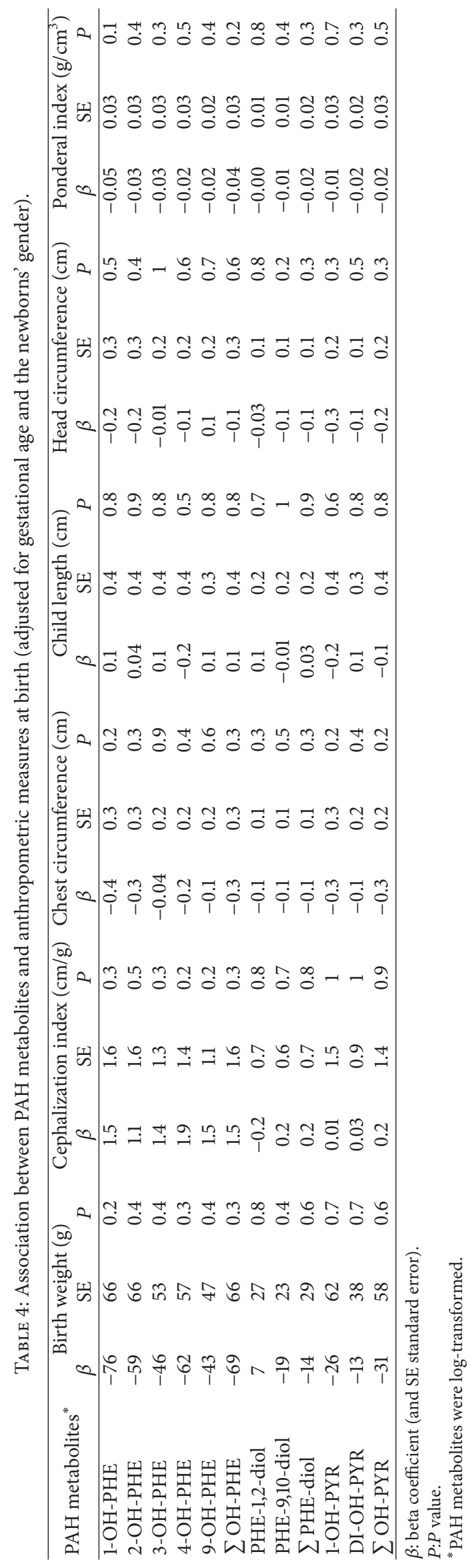




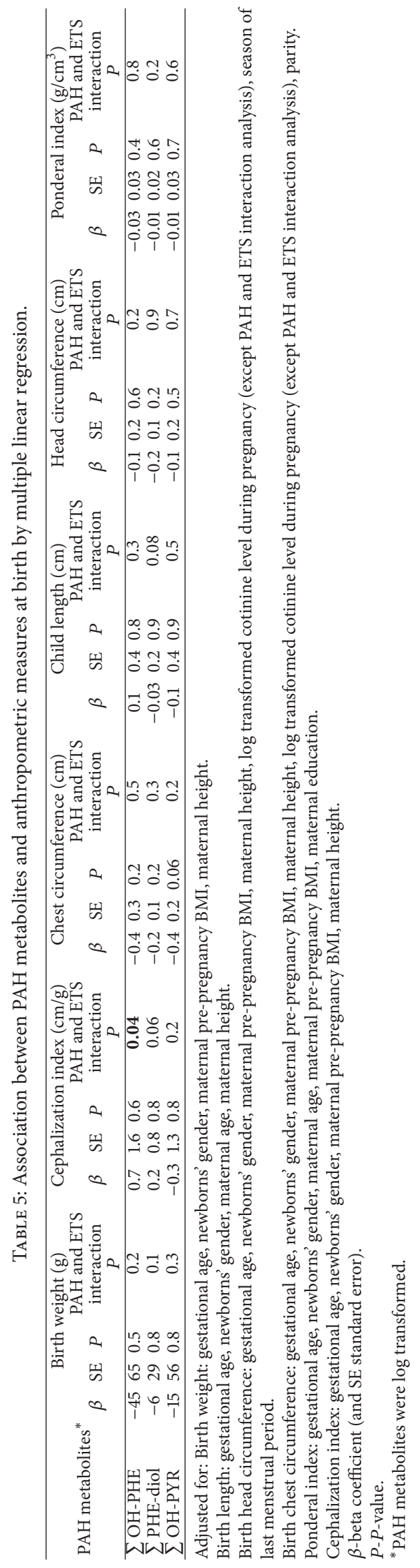


associated with significantly reduced birth weight in Krakow Caucasians $(P<0.01)$ and in NYC African Americans $(P<0.05)$, but not in NYC Dominicans $[9,11]$. A recently published study indicated that PAH exposure appears to exert the greatest adverse effect on fetal growth during the first trimester [13]. This kind of analysis was not feasible in our study. No association was found between 1-OH-PYR levels and any of pregnancy outcomes in the two recent studies conducted in Saudi Arabia and Japan [5, 37].

The impact of PAH exposure on the cephalization index was reported in an earlier study by Choi et al. (2008) [12]. Increased cephalization index, the ratio of head size to birth weight, may suggest that growth restriction might induce a "brain-sparing" process at developmental expense of other organs. This could be of particular concern taking into account that children born with a larger head circumference relative to the body weight score significantly lower in neurodevelopmental tests, IQ, and school performance and are at a greater risk of subsequent morbidity and mortality [12]. Perera et al. (2004) reported that combined exposure to high ETS and high BaP-DNA adducts had a significant multiplicative effect on birth weight $(P=0.04)$ and head circumference $(P=0.01)$ [38]. In the present study the interaction effect of PAH metabolites and cotinine was significant only for the cephalization index; for other birth outcomes, the pattern of association, although not statistically significant, was similar to that observed by Perera et al. (2004) [38].

Fetal toxicity caused by PAH and ETS may result from antiestrogenic effects [39], binding of constituents to human aryl hydrocarbon receptor and subsequently inducing cytochrome P450 enzymes [40], DNA damage [41-43], and binding of receptors for placental growth factors resulting in a decreased exchange of oxygen and nutrients or direct effect of carbon monoxide [7, 38].

4.3. Confounders. Majority of the studies published in this field have focused on the known possible confounding variables such as child gender, gestational age, marital and educational status of pregnant women, prepregnancy BMI, and season of the last menstrual period, which were also addressed in our analysis. By restricting our study population to healthy women without serious pregnancy complications and to single pregnancies, we were able to eliminate several confounding factors.

4.4. Strengths and Limitations. The current analysis is based on the Polish Mother and Child Cohort Study (REPRO_PL cohort). The prospective study design with well-assessed exposure levels based on biomarker measurements (cotinine, PAH metabolites) is an important advantage of the current analysis. Thanks to it we have addressed some of the traditional limitations such as exposure misclassification and retrospective or cross-sectional exposure assessment. Additionally, a series of detailed questionnaires (collected once in each trimester of pregnancy and one week after delivery) allow for reliable assessment of coexposure and confounding variables.

The current study results may be limited by a modest sample size; however it has sufficient power to perform the presented analysis. As it was mentioned above, the biomarkers were measured only at a single time point which may constitute an additional limitation of our study. Finally, although creatinine correction is commonly used for urinary biomarkers, in some studies the specific gravity was used instead of creatinine in order to adjust PAH metabolites for urine dilution. However, specific gravity is highly correlated with creatinine [44]. Therefore an overcorrection for urine dilution is not expected in this study, especially because the results from the very diluted urine samples have been discarded.

\section{Conclusions}

This study provides evidence that combined exposure of pregnant women to common environmental pollutants such as PAH and ETS might adversely affect fetal development. Thus, reduction of human exposure to these mixtures of hazardous compounds would in particular result in substantial health benefits for newborns and improve prevention of restrictions in their subsequent development.

\section{Conflict of Interests}

The authors declare that they have no conflict of interests regarding the publication of this paper.

\section{Acknowledgments}

The authors would like to thank all the women who participated in this study and all the staff involved in the project realization. The study was supported by the project "Prenatal and Postnatal Exposure to Tobacco Smoke, PAH, and Heavy Metals and the Risk of Respiratory Diseases, Allergy, and Poor Mental and Physical Development" funded by the Grant PNRF-218-AI-1/07 from Norway through the Norwegian Financial Mechanism within the Polish-Norwegian Research Fund and the project financed with a Grant for statutory activity IMP 10.6/2013.

\section{References}

[1] IARC International Agency for Research on Cancer, Some NonHeterocyclic Polycyclic Aromatic Hydrocarbons and Some Related Exposures, vol. 92 of IARC Monographs on the Evaluation of Carcinogenic Risks to Humans, World Health Organization, Lyon, France.

[2] D. H. Phillips, "Polycyclic aromatic hydrocarbons in the diet," Mutation Research, vol. 443, no. 1-2, pp. 139-147, 1999.

[3] C. E. Boström, P. Gerde, A. Hanberg et al., "Cancer risk assessment, indicators, and guidelines for polycyclic aromatic hydrocarbons in the ambient air," Environmental Health Perspectives, vol. 110, supplement 3, pp. 451-488, 2002.

[4] European Food Safety Agency, "Polycyclic aromatic hydrocarbons in food. Scientific opinion on the panel on contaminants in the food chain," The EFSA Journal, vol. 724, pp. 1-114, 2008.

[5] I. Al-Saleh, A. Alsabbahen, N. Shinwari et al., "Polycyclic aromatic hydrocarbons (PAHs) as determinants of various 
anthropometric measures of birth outcome," Science of the Total Environment, vol. 444, pp. 565-578, 2013.

[6] F. P. Perera, D. Tang, R. Whyatt, S. A. Lederman, and W. Jedrychowski, "DNA damage from polycyclic aromatic hydrocarbons measured by benzo[a]pyrene-DNA adducts in mothers and newborns from Northern Manhattan, the World Trade Center Area, Poland, and China," Cancer Epidemiology Biomarkers and Prevention, vol. 14, no. 3, pp. 709-714, 2005.

[7] J. Dejmek, I. Solanský, I. Beneš, J. Leníček, and R. J. Šrám, “The impact of polycyclic aromatic hydrocarbons and fine particles on pregnancy outcome," Environmental Health Perspectives, vol. 108, no. 12, pp. 1159-1164, 2000.

[8] F. P. Perera, R. M. Whyatt, W. Jedrychowski et al., "Recent developments in molecular, epidemiology: a study of the effects of environmental polycyclic aromatic hydrocarbons on birth outcomes in Poland," The American Journal of Epidemiology, vol. 147, no. 3, pp. 309-314, 1998.

[9] F. P. Perera, V. Rauh, W. Y. Tsai et al., "Effects of transplacental exposure to environmental pollutants on birth outcomes in a multiethnic population," Environmental Health Perspectives, vol. 111, no. 2, pp. 201-205, 2003.

[10] F. P. Perera, V. Rauh, R. M. Whyatt et al., "A summary of recent findings on birth outcomes and developmental effects of prenatal ETS, PAH, and pesticide exposures," NeuroToxicology, vol. 26, no. 4, pp. 573-587, 2005.

[11] H. Choi, W. Jedrychowski, J. Spengler et al., "International studies of prenatal exposure to polycyclic aromatic hydrocarbons and fetal growth," Environmental Health Perspectives, vol. 114, no. 11, pp. 1744-1750, 2006.

[12] H. Choi, V. Rauh, R. Garfinkel, Y. Tu, and F. P. Perera, "Prenatal exposure to airborne polycyclic aromatic hydrocarbons and risk of intrauterine growth restriction," Environmental Health Perspectives, vol. 116, no. 5, pp. 658-665, 2008.

[13] H. Choi, L. Wang, X. Lin, J. D. Spengler, and F. P. Perera, "Fetal window of vulnerability to airborne polycyclic aromatic hydrocarbons on proportional intrauterine growth restriction," PLoS ONE, vol. 7, no. 4, Article ID e35464, 2012.

[14] K. Polańska, W. Hanke, W. Sobala, S. Brzeźnicki, and D. Ligocka, "Exposure to polycyclic aromatic hydrocarbons and newborn biometric indicators," International Journal of Occupational Medicine and Environmental Health, vol. 23, no. 4, pp. 339-346, 2010.

[15] H. Bassan, M. Bassan, A. Pinhasov et al., "The pregnant spontaneously hypertensive rat as a model of asymmetric intrauterine growth retardation and neurodevelopmental delay," Hypertension in Pregnancy, vol. 24, no. 3, pp. 201-211, 2005.

[16] Y. Leitner, A. Fattal-Valevski, R. Geva et al., "Neurodevelopmental outcome of children with intrauterine growth retardation: a longitudinal, 10-Year prospective study," Journal of Child Neurology, vol. 22, no. 5, pp. 580-587, 2007.

[17] F. P. Perera, V. Rauh, R. M. Whyatt et al., "Effect of prenatal exposure to airborne polycyclic aromatic hydocarbons on neurodevelopment in the first 3 years of life among inner-city children," Environmental Health Perspectives, vol. 114, no. 8, pp. 1287-1292, 2006.

[18] F. P. Perera, Z. Li, R. Whyatt et al., "Prenatal airborne polycyclic aromatic hydrocarbon exposure and child IQ at age 5 years," Pediatrics, vol. 124, no. 2, pp. e195-e202, 2009.

[19] F. P. Perera, S. Wang, J. Vishnevetsky et al., "Polycyclic aromatic hydrocarbons-aromatic DNA adducts in cord blood and behavior scores in New York city children," Environmental Health Perspectives, vol. 119, no. 8, pp. 1176-1181, 2011.
[20] S. C. Edwards, W. Jedrychowski, M. Butscher et al., "Prenatal exposure to airborne polycyclic aromatic hydrocarbons and children's intelligence at 5 years of age in a prospective cohort study in Poland," Environmental Health Perspectives, vol. 118, no. 9, pp. 1326-1331, 2010.

[21] S. Wang, S. Chanock, D. Tang et al., "Effect of gene-environment interactions on mental development in African American, Dominican, and Caucasian mothers and newborns," Annals of Human Genetics, vol. 74, no. 1, pp. 46-56, 2010.

[22] K. Polańska, W. Hanke, J. Gromadzińska et al., "Polish mother and child cohort study-defining the problem, the aim of the study and methodological assumptions," International Journal of Occupational Medicine and Environmental Health, vol. 22, no. 4, pp. 383-391, 2009.

[23] J. Stragierowicz, K. Mikolajewska, M. Zawadzka-Stolarz, and K. Mikołajewska, "Estimation $\mathrm{f}$ cutoff values of cotinine in urine and saliva for pregnant women in Poland," BioMed Research International, vol. 2013, Article ID 386784, 11 pages, 2013.

[24] N. L. Benowitz, P. Jacob, K. Ahijevych et al., "Biochemical verification of tobacco use and cessation," Nicotine and Tobacco Research, vol. 4, no. 2, pp. 149-159, 2002.

[25] K. Polanska, W. Hanke, G. Dettbarn et al., "The determination of polycyclic aromatic hydrocarbons in the urine of nonsmoking Polish pregnant women," Science of the Total Environment, vol. 487, pp. 102-109, 2014.

[26] J. Jacob, G. Raab, V. Soballa et al., "Cytochrome P450-mediated activation of phenanthrene in genetically engineered V79 Chinese hamster cells," Environmental Toxicology and Pharmacology, vol. 1, no. 1, pp. 1-11, 1996.

[27] H. Vollmann, H. Becker, M. Corell et al., "Beitraege zur Kenntnis des Pyrens und seiner Derivate," Justus Liebigs Annalen der Chemie, vol. 53, no. 1, pp. 1-159, 1937.

[28] A. Seidel, A. Spickenheuer, K. Straif et al., "New biomarkers of occupational exposure to polycyclic aromatic hydrocarbons," Journal of Toxicology and Environmental Health A, vol. 71, no. 1112, pp. 734-745, 2008.

[29] H. Choi, F. Perera, A. Pac et al., "Estimating individuallevel exposure to airborne polycyclic aromatic hydrocarbons throughout the gestational period based on personal, indoor, and outdoor monitoring," Environmental Health Perspectives, vol. 116, no. 11, pp. 1509-1518, 2008.

[30] K. Polańska, W. Hanke, W. Sobala, S. Brzeźnicki, and D. Ligocka, "Predictors of environmental exposure to polycyclic aromatic hydrocarbons among pregnant women-prospective cohort study in Poland," International Journal of Occupational Medicine and Environmental Health, vol. 24, no. 1, pp. 8-17, 2011.

[31] C. C. Tonne, R. M. Whyatt, D. E. Camann, F. P. Perera, and P. L. Kinney, "Predictors of personal polycyclic aromatic hydrocarbon exposures among pregnant minority women in New York City," Environmental Health Perspectives, vol. 112, no. 6, pp. 754-759, 2004.

[32] S. Llop, F. Ballester, M. Estarlich et al., "Urinary 1-hydroxypyrene, air pollution exposure and associated life style factors in pregnant women," Science of the Total Environment, vol. 407, no. 1, pp. 97-104, 2008.

[33] M. Wilhelm, J. Hardt, C. Schulz, and J. Angerer, "New reference value and the background exposure for the PAH metabolites 1hydroxypyrene and 1- and 2-naphthol in urine of the general population in Germany: basis for validation of human biomonitoring data in environmental medicine," International Journal of Hygiene and Environmental Health, vol. 211, no. 3-4, pp. 447453, 2008. 
[34] C. Schulz, M. Wilhelm, U. Heudorf, and M. Kolossa-Gehring, "Reprint of "update of the reference and HBM values derived by the German Human Biomonitoring Commission"', International Journal of Hygiene and Environmental Health, vol. 215, no. 2, pp. 150-158, 2012.

[35] Directive 2004/107/EC of The European Parliament and of the Council of 15 December 2004 relating to arsenic, cadmium, mercury, nickel and polycyclic aromatic hydrocarbons in ambient air. Directive 2004/107/EC.

[36] Voivodship Inspectorates for Environmental Protection, http:// www.wios.lodz.pl/serwis.

[37] Y. Suzuki, M. Niwa, J. Yoshinaga, Y. Mizumoto, S. Serizawa, and H. Shiraishi, "Prenatal exposure to phthalate esters and PAHs and birth outcomes," Environment International, vol. 36, no. 7, pp. 699-704, 2010.

[38] F. P. Perera, V. Rauh, R. M. Whyatt et al., "Molecular evidence of an interaction between prenatal environmental exposure and birth outcomes in a multiethnic population," Environmental Health Perspectives, vol. 112, no. 5, pp. 626-630, 2004.

[39] Q. Q. Bui, M. B. Tran, and W. L. West, "A comparative study of the reproductive effects of methadone and benzo[a]pyrene in the pregnant and pseudopregnant rat," Toxicology, vol. 42, no. 2-3, pp. 195-204, 1986.

[40] D. K. Manchester, S. K. Gordon, C. L. Golas, E. A. Roberts, and A. B. Okey, "Ah receptor in human placenta: stabilization by molybdate and characterization of binding of 2,3,7,8-tetrachlorodibenzo-p-dioxin, 3-methylcholanthrene, and benzo(a)pyrene," Cancer Research, vol. 47, no. 18, pp. 48614868, 1987.

[41] M. S. Meyn, "Ataxia-telangiectasia and cellular responses to DNA damage," Cancer Research, vol. 55, no. 24, pp. 5991-6001, 1995.

[42] C. J. Nicol, M. L. Harrison, R. R. Laposa et al., "A teratologic suppressor role for p53 in benzo [a] pyrenetreated transgenic p53-deficient mice," Nature Genetics, vol. 10, pp. 181-187, 1995.

[43] K. A. Wood and R. J. Youle, "The role of free radicals and p53 in neuron apoptosis in vivo," The Journal of Neuroscience, vol. 15, no. 8, pp. 5851-5857, 1995.

[44] D. B. Barr, L. C. Wilder, S. P. Caudill, A. J. Gonzalez, L. L. Needham, and J. L. Pirkle, "Urinary creatinine concentrations in the U.S. population: implications for urinary biologic monitoring measurements," Environmental Health Perspectives, vol. 113, no. 2, pp. 192-200, 2005. 


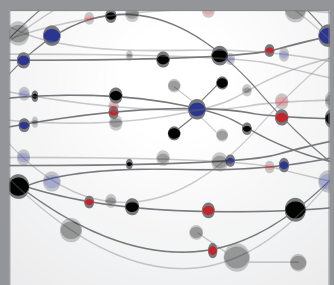

The Scientific World Journal
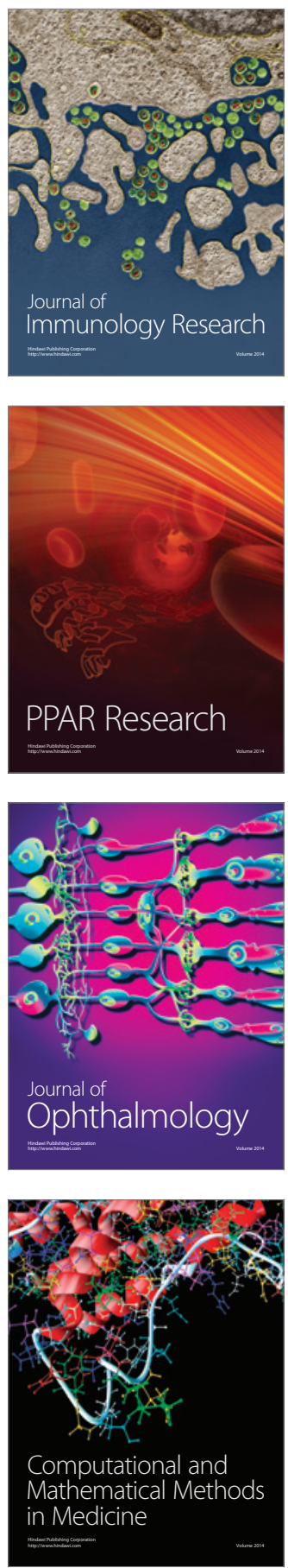

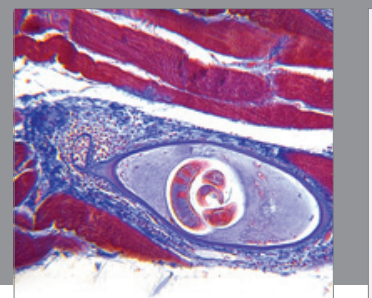

Gastroenterology

Research and Practice
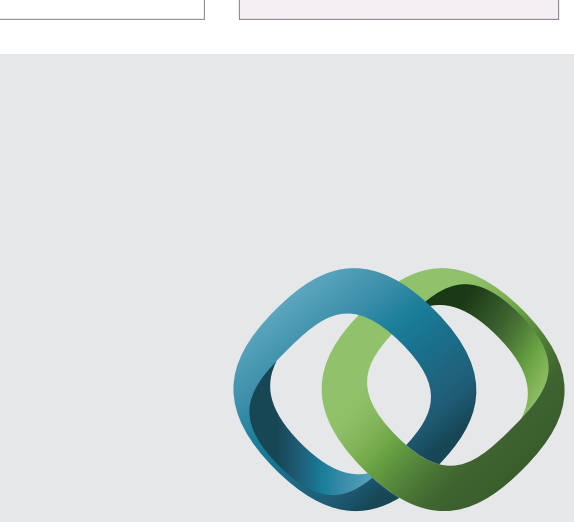

\section{Hindawi}

Submit your manuscripts at

http://www.hindawi.com
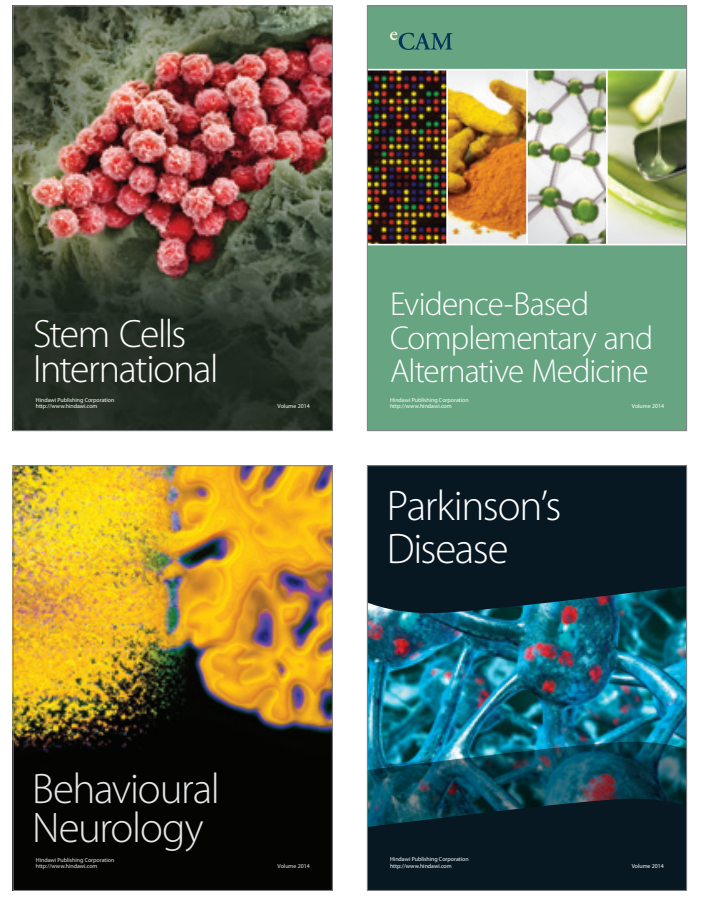
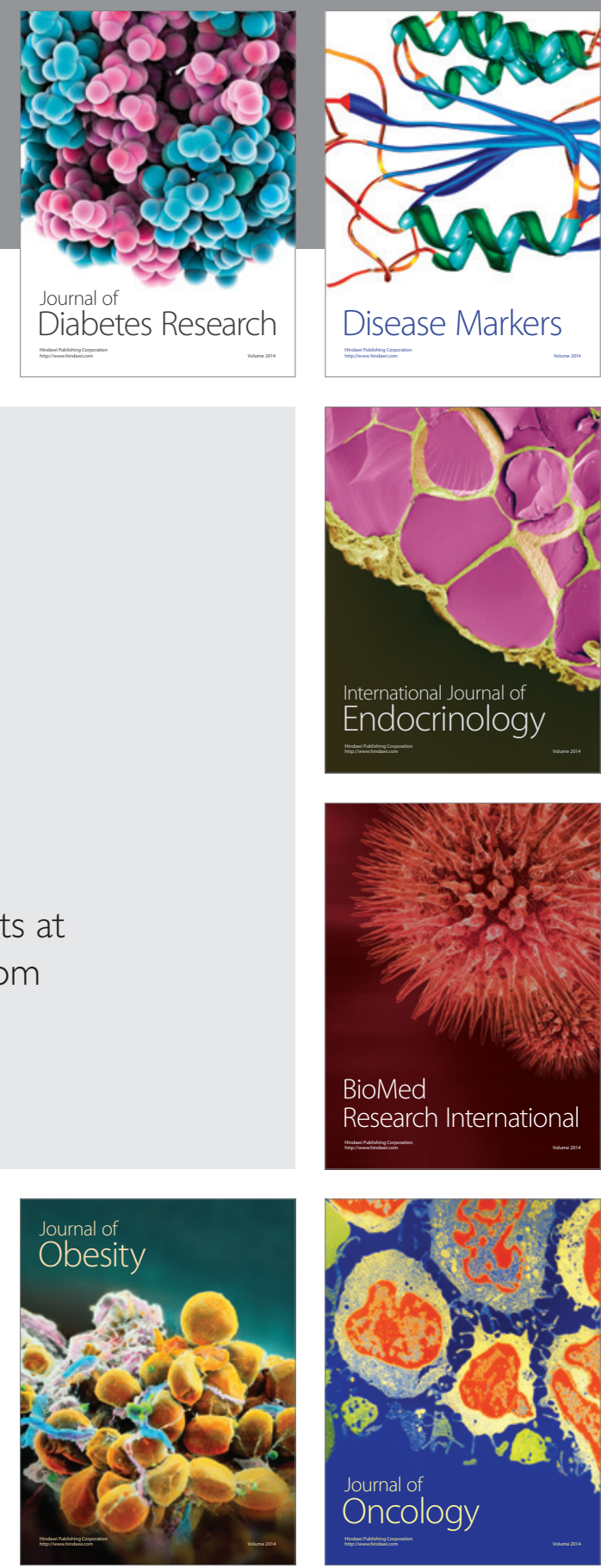

Disease Markers
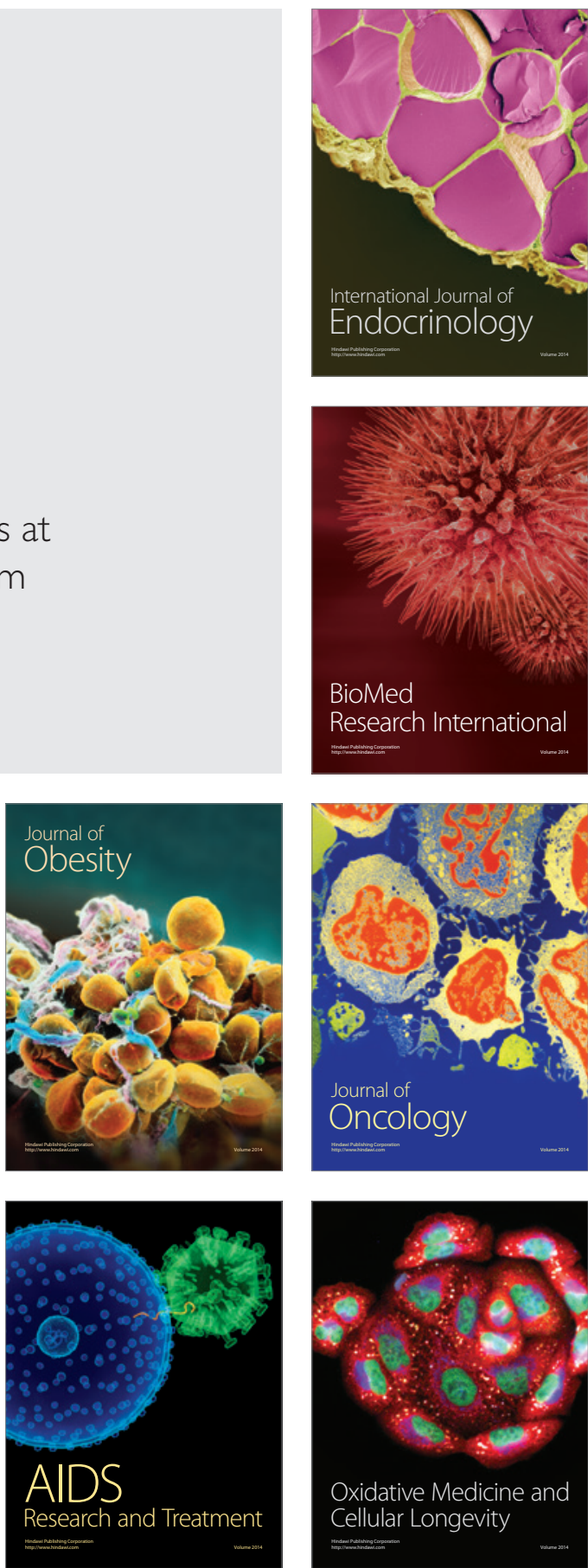